Article

\title{
The Use of Visual Decision Support Tools in an Interactive Stakeholder Analysis - Old Ports as New Magnets for Creative Urban Development
}

\author{
Karima Kourtit * and Peter Nijkamp \\ Department of Spatial Economics, VU University, De Boelelaan 1105, Amsterdam 1081 HV, \\ The Netherlands; E-Mail: p.nijkamp@vu.nl \\ * Author to whom correspondence should be addressed; E-Mail: k.kourtit@vu.nl; \\ Tel.: +31-20-598-6090; Fax: +31-20-598-6004.
}

Received: 5 September 2013 / Accepted: 30 September 2013 / Published: 17 October 2013

\begin{abstract}
Port cities are historically important breeding places of civilization and wealth, and act as attractive high-quality and sustainable places to live and work. They are core places for sustainable development for the entire spatial system as a result of their dynamism, which has in recent years reinforced their position as magnets in a spatial-economic force field. To understand and exploit this potential, the present study presents an analytical framework that links the opportunities provided by traditional port areas/cities to creative, resilient and sustainable urban development. Using evidence-based research, findings are presented from a case study by employing a stakeholder-based model - with interactive visual support tools as novel analysis methods - in a backcasting and forecasting exercise for sustainable development. The empirical study is carried out in and around the NDSM-area, a former dockyard in Amsterdam, the Netherlands. Various future images were used - in an interactive assessment incorporating classes of important stakeholders - as strategic vehicles to identify important policy challenges, and to evaluate options for converting historical-cultural urban port landscapes into sustainable and creative hotspots, starting by reusing, recovering, and regenerating such areas. This approach helps to identify successful policy strategies, and to bring together different forms of expertise in order to resolve conflicts between the interests (or values) of a multiplicity of stakeholders, with a view to stimulating economic vitality in combination with meeting social needs and ensuring the conservation of eco-systems in redesigning old port areas. The results indicate that the interactive policy support tools developed for the case study are fit for purpose, and are instrumental in designing sustainable urban port areas.
\end{abstract}


Keywords: port city; urban landscape; multifunctional landscape; stakeholder-based model; backcasting; forecasting; sustainable development

\section{Introduction}

Ports are the oldest logistics centers in international trade and have always been economic powerhouses in transport systems. Already in the 18th century, the grandfather of modern economics, Adam Smith, was referring to seashores and riverbanks as poles of economic wealth, as their openness allowed them to establish trade relationships with the rest of the world. In the course of time, ports have developed as major logistic magnets generating trade and transport connections all over the world. In addition, consequently, many port areas laid the foundation for an increase in welfare, not only for the direct urban or industrial areas concerned, but also for the hinterlands connected with these areas, and for all other places served by these ports. Over the course of time, port areas have become hotspots of economic activity. The ports' history, culture and economy originate predominantly from their adjacent oceans, seas, lakes and rivers. They acted as (centripetal and centrifugal) transportation hubs that favored openness in trade in a global economy. They were also often the scene of socio-economic inequality, with a strong tension between white-collar managers ('barons') and blue-collar workers. Especially with the advent of the Industrial Revolution (mid-19th century), ports became symbols of a new industrial age, thanks to advanced steamships, large-scale shipyards, etc.

In the past few decades, many port areas all over the world went through a phase of decline, as they became outdated, or were replaced by modern facilities elsewhere. This has left many cities with large harborfront areas that were dilapidated and showed clear signs of environmental decay and even poverty. Such brownfield sites have increasingly become a source of policy concern, and have stimulated the emergence of various urban land-use initiatives in order to exploit the hitherto unused economic, social, logistic, cultural and environmental opportunities of such areas. As a result, in recent years many cities have developed new policy mechanisms for upgrading their port brownfield sites through harborfront and seafront development (e.g., the London Dockyards, the Kop van Zuid in Rotterdam, and waterfronts in Cape Town, New York, Yokohama, Singapore, Helsinki, etc.). The two key phrases in this drastic land use conversion are: sustainable development and creative sector stimulation. Port areas may thus become precious containers of past architectural and socio-cultural heritage and expression. But this heritage is not a passive phenomenon, but may be the basis for innovative developments in urban areas by offering new residential, business, and tourist facilities in the short and middle to long term.

Harborfront development and port revitalization are all part of urban gentrification processes. This has not only a physical dimension (e.g., land use, real estate, infrastructure), but also a socio-economic dimension, (e.g., labor force participation, inclusion of less privileged groups, cultural diversity). We refer in this context to relevant studies on these issues by Atkinson [1], Butler [2] or Watt [3]. Harborfront have many things in common, but they may differ in terms of their social and economic functions and activities, where important aspects related to urban renewal and revitalization-including policy scenarios for creative and sustainable urban development - are considered to be necessary for 
effective interventions. This means that a reformulation of port cities' policies may require 'out of the box thinking', while bringing together different perspectives, original interpretations, imagination, and appropriate tools for conflict management. This calls for imagining a future with a full understanding of the consequences before creating it. This may lead to a new process of (re)designing port cities ranging from small to large interventions regarding the functionality and architecture of the port areas concerned - interventions which preserve historical heritage (tangible and intangible) in combination with smart modern buildings and facilities. This task has to be undertaken against the background of a complex urban carousel of challenges in order to enhance the socio-economic and ecological resilience of the port area - in relation to the city system - and to activate many initiatives that would convert historico-cultural urban port landscapes into sustainable and creative hotspots, starting by reusing, recovering, and regenerating such areas. However, the high degree of tension between different stakeholders' needs and local government strategies or urban planning initiatives related to these port areas may frustrate sustainable development. This presents the challenge to review the port city system from the perspective of new paradigms, based, for example, on 'creative minds' principles [4]. For the definition of creative minds, we use the classification created by TNO [5] as a basis for the interviews. The definition of all these branches of the creative industries is based on the standard industrial classification [6] from Statistics Netherlands (CBS), which contains three types of creative firms, viz. arts, media and entertainment, and creative business services. Table 1 shows which economic activities are classified in these three groups.

Such novel ways of thinking are increasingly required and linked to new, efficient and effective urban planning, governance, and management processes in order to finally ensure broad stakeholder acceptance. This calls for new evaluation and assessment tools and techniques in order to confront decision makers with a consistent set of sustainable strategic choices and changes (by extending the range of possibilities and preferences) in relation to creative urban development, while considering a stakeholder participation-based approach ('bottom up' strategy) [7,8], using, for example, interactive methods based on what we call the 'urban Facebook' concept. In this context, such a concept could be an important analytical vehicle, through a multilayered bottom-up approach, to systematically map out various local stakeholders' needs, knowledge domains, interventions and perspectives (backcasting) into new visions and urban development strategies [9]. These various stakeholders may be characterized as early adopters or social innovators [10], and hence their behavior may be seen as trend-setting for a much larger population.

The present paper aims to further develop the multilayered stakeholder-based framework by introducing and elaborating what we call the 'urban Facebook for urban facelifts', an approach that is extensively supported by high-quality visual assessment tools for mapping novel redevelopment initiatives, in order to be able to identify and understand specific local needs and necessary spatial developments. It offers a basis for interventions that tackle present and future urban problems, foundations, challenges, and consequences (in combination with urban scenarios, which are essentially strategic future image experiments based on, for example, the imagining of future port cities' positions) designed to achieve the desired goals related to urban strategic visions, while, in addition, this approach may encourage the urban economy to stay (internationally) competitive. 
Table 1. The classifications of the stakeholders 'creative minds' in the creative industries and the SBI codes: Arts, Media, and Creative Business Services (Source: [4]).

\begin{tabular}{|c|c|c|c|}
\hline \multirow{2}{*}{ Main domains } & \multirow{2}{*}{ Segments } & \multicolumn{2}{|r|}{ Standard Industrial Classification (SBI) } \\
\hline & & SBI-1993 & Description \\
\hline \multirow{7}{*}{ Art } & \multirow{7}{*}{$\begin{array}{l}\text { Music \& Performing Arts, } \\
\text { Museums, Theatres and } \\
\text { Art galleries }\end{array}$} & 92311 & Performing of live stage art \\
\hline & & 92312 & Production of live stage art \\
\hline & & 92313 & Performing of casting art \\
\hline & & 92321 & Theatres, concert rooms, concert buildings \\
\hline & & 92323 & Services for performing art \\
\hline & & 92521 & Art galleries, exposition areas \\
\hline & & 92522 & Museums \\
\hline \multirow{15}{*}{ Media } & \multirow{15}{*}{$\begin{array}{l}\text { Film, TV, Radio, } \\
\text { Photography, Publishing } \\
\text { Broadcasting, Amusement } \\
\text { and entertainment, Press }\end{array}$} & 2211 & Publishers of books \\
\hline & & 2212 & Publishers of periodicals \\
\hline & & 2213 & Publishers of magazines \\
\hline & & 2214 & Publishers of sound recording \\
\hline & & 2215 & Other publishers \\
\hline & & 74811 & Photography \\
\hline & & 92111 & Production of movies \\
\hline & & 92112 & Supporting services for movie production \\
\hline & & 92201 & Broadcasting organizations \\
\hline & & 92202 & Production of radio- and TV programs \\
\hline & & 92203 & Supporting activities for radio and TV \\
\hline & & 9212 & Distribution of movies \\
\hline & & 9213 & Cinemas \\
\hline & & 92343 & Other entertainment \\
\hline & & 9240 & Press-, news agencies; journalists \\
\hline \multirow{5}{*}{$\begin{array}{l}\text { Creative } \\
\text { Business } \\
\text { Services }\end{array}$} & Advertising and & 74201 & Architecture and technical design \\
\hline & Marketing, Information & 74202 & Technical design/advice, e.g., city building \\
\hline & and Technology, & 74401 & Commercial design- and consultancy agencies \\
\hline & Architecture, Design and & 74402 & Other commercial services \\
\hline & Fashion & 74875 & Interior and fashion designers \\
\hline
\end{tabular}

Our empirical case study was carried out in and around the NDSM-area, a former dockyard in Amsterdam, the Netherlands. This study was undertaken in the context of transitional urban port systems for sustainable urban development, from a forward-looking long-term strategic policy perspective (a combination of backcasting and forecasting approaches), which meets the needs, and addresses the concerns, of its various users, where vision and strategy have to fit well with their environment. This bottom-up approach is, inter alia, based on information collected, during interviews, from different stakeholders with a wide range of interests in relation to the area, followed by the use of a strength-weakness opportunities-threats (SWOT) analysis methodology with visual support tools. All this is done in order to develop a collective and quantitative evaluation of the socio-economic performance of the NDSM, which focuses on its physical use, characteristics, and historical landscape attributes.

This paper is organized as follows. Section 2 is devoted to an overview of the NDSM Wharf as a new development core in Amsterdam. Then, Section 3 presents the methodology for assessing 
the NDSM-district, whereby past, current and future effects are assessed from a broad perspective. Section 4 then introduces the SWOT analysis, which leads to the design and presentation of a conceptual 'urban Facebook' for an NDSM Facelift. In Section 5, the urban Facebook is elaborated, including the database employed and the architecture of our exploratory data analysis, leading ultimately to the identification of the most suitable 'Urban Facelift'. This information is then further used in Section 6, which presents the results of our operational 'urban Facebook' by linking the present performance of the area to various future perspectives and urban future images for the revitalization of the NDSM. Finally, Section 7 makes some retrospective and prospective observations on our policy research, in particular on the NDSM district.

\section{The NDSM Wharf as a New Development Experiment}

The NDSM, a former dockyard on the northern banks of the River IJ in Amsterdam, has become a culture-based creativity and social innovation district with a great diversity of trendy facilities and seemingly uncontrolled land use. This area is sometimes called the NDSM-Safari (see Figure 1).

Figure 1. Map of the NDSM-Safari in Amsterdam.

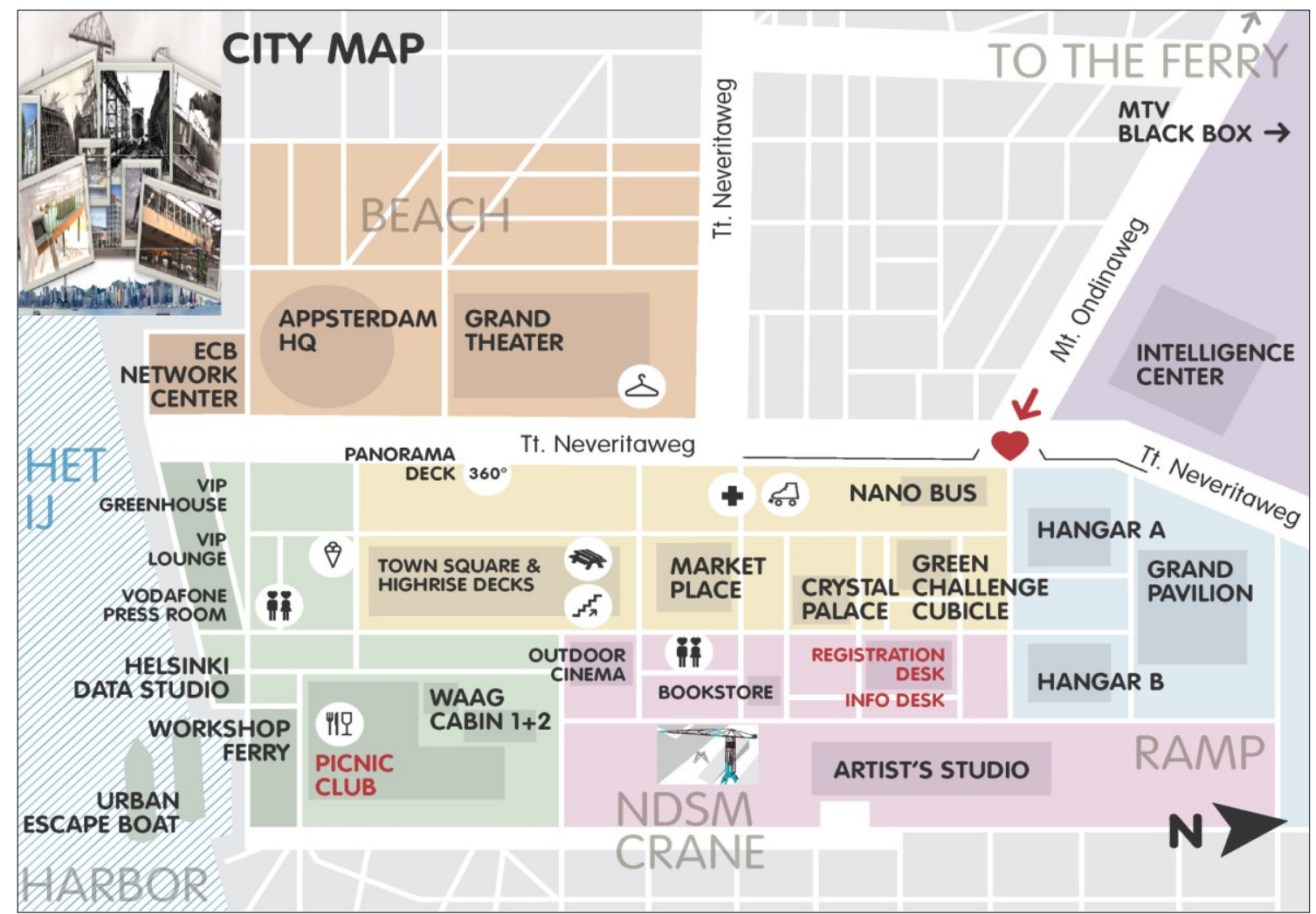

Source: PICNIC 2011 in de steigers; by Waag Society (Institute for art, science and technology. Waag Society is situated in Amsterdam and develops creative technology for social innovation).

The 'NDSM-Safari' serves as a laboratory of informal and formal living and working spaces with new infrastructure for the collaboration of creative minds - a bubbly mix of activities directly involved in the development and production of cultural, creative and innovative products and services - for new urban development and advanced urban competitiveness. It is hoped that creative minds will develop 
innovative ideas and suggest new pathways to sustainable development, and act as central breeding places for a broad range of various stakeholders in search of original concepts in a globalizing competitive world [4]. From this perspective, creative minds have an exceptional innovation potential in terms of both ideas and practices. Therefore, they may act as effective growth engines in modern cities.

The existing 'bohemian landscape' of the NDSM shipyard, with its historical background, exploits its rough and untouched diversity and flexibility characteristics. It has gone through a number of different phases generated by the creative minds of the district and renews itself often, so its creative bubble of mixed functionality and working class population [11] is well-recognized and a great inspiration for the next stage of the development of the urban core. It can provide many illustrations of an informal repositioning and redevelopment of a district with a great potential, but the local authority has no clear long-term strategic view or commitment regarding the potential of the 'creative minds'.

The future form of the NDSM-Safari is already taking shape. However, as just mentioned, it lacks both long-term strategies (e.g., a solid and integrated breeding place policy) to meet the important needs and preferences of the various stakeholders and guarantees by the local authority to create a 'sustainable home' for various professionals, businesses, and artists. And it should not remain only as a temporary 'project', but become a new part of a future productive urban landscape instead of an isolated breeding place. This means that viable strategic options have to be interpreted and discussed in an integrated multilayered framework in order to provide a sound basis for the possible preparation of conditions for the further redevelopment of the NDSM location as a district for the production of urban culture. There, place-based characteristics and opportunities, and historical landscape attributes may draw (more) creative minds and innovative business models to certain sites, where they can share and combine their (international) knowledge and expertise with challenging socio-economic opportunities. This requires an understanding of more than just the commercial side of this district or the decrease of the 20 sub-clusters located there, in order to realize their common interests in the NDSM vision and come to a general strategic core policy.

It is noteworthy that the presence and experience (individual visions, preferences and values) of creative minds can create critical conditions for the level of attractiveness of this historical and cultural district as a favorable concentration of geographical space (clusters). In and around the NDSM district, the various stakeholders can experience the inspiring urban atmosphere and 'cool image' (e.g., visual features, reputation), which are crucial for creative and innovative working processes. The value, for instance, that firms put on the NDSM-district regarding their location-decisions based on their preferences intensities and criteria for visual assets may positively influence these firms' (business) performance and strategic choices. These, in turn, may bring about positive socio-economic achievements, which may enhance the attractiveness of port cities and regions and, ultimately, achieve a high degree of sustainability and competitive advantage [12]. In order to generate positive externalities, regions and cities have to listen to the various stakeholders and provide unique geographical and location conditions and facilities - beyond other competitive assets - in order to attract talent and firms to relatively deprived regions. This issue has been repeatedly addressed in the past by the local authority.

From this perspective, the present situation regarding the sustainable development of NDSM calls for a careful evaluation of this hotspot, which assumes that this 'port system within a system' of the 
city Amsterdam [13] will create the possibilities and new opportunities for the entrance of new cultural and innovative activities such as 'hip' cultural areas, which can give a sense of freedom to (new) creative minds. Hence, the main aim of this empirical research is to develop and support a new and promising future orientation for the district's sustainable development, based on a multilayered stakeholder-oriented approach (which, in redesigning the port area, attempts to resolve conflicts between the interests or values of a multiplicity of stakeholders, while favoring economic prosperity in combination with meeting social needs).

\section{Research Methodology}

Our central methodological research task is to develop a multilayered stakeholder-based analysis framework that is fit-for-purpose for the NDSM-district, and is able to analyze its future potential, using interactive methods, where the form of the urban facelift embraces different levels of urban revitalization for the district's sustainable development.

This conceptual evaluation framework can be characterized as a pro-active process of choosing viable strategic choice(s) and a facelift for areas based on various stakeholders' preferences and values, in the form of a SWOT analysis. In this analysis, the indicators that can influence the constellation of socio-economic characteristics of port and city systems were converted into a long list of important criteria and presented to the interviewees. This process can be systematically divided into six steps, with regard to the socio-economic context (based on the 'Strategic Choice Analysis' (SCA) approach [14], starting from the NDSM development assessment, and ending with conclusions and the identification of policy recommendations for a new urban facelift (see Figure 2). This approach can also be seen as a toolkit for the sustainable development of other port cities, cities and regions, which are aiming to enhance their dynamic profile.

Figure 2. Stepwise presentation of the evaluation to identify the most effective strategic choices, images, and opportunities for the sustainable development of the NDSM district.

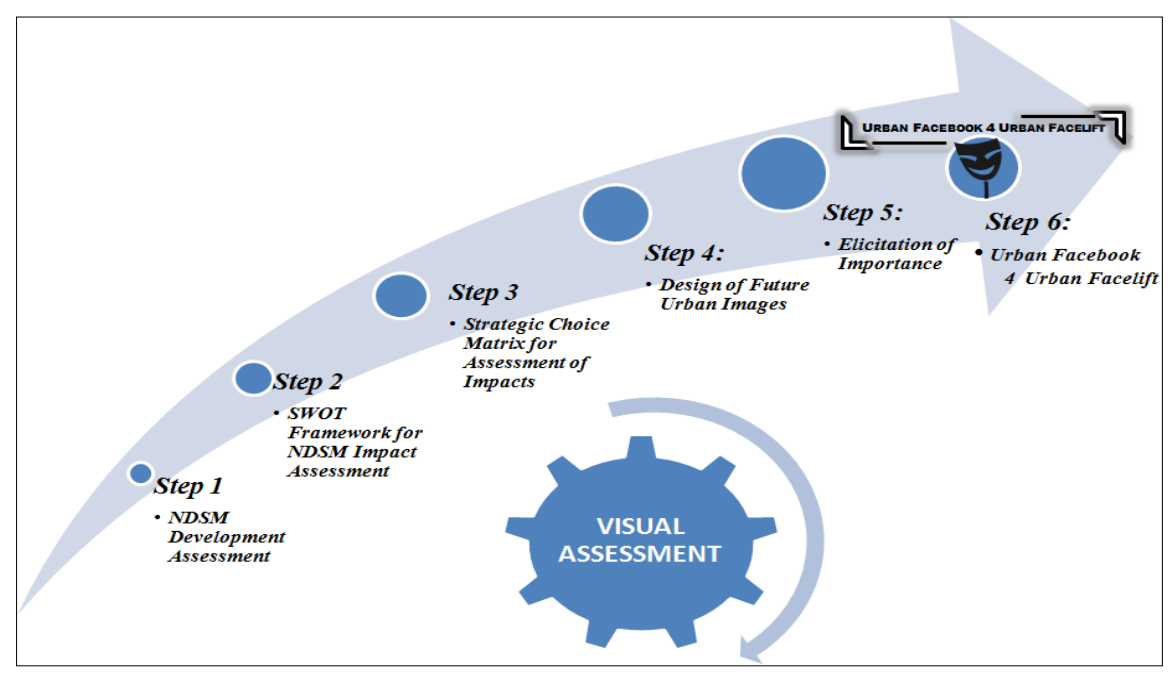

This process starts with the assessment of the physical use, characteristics, and historical landscape attributes and developments of the NDSM district, and ultimately identifies general strategic ideas for its future sustainable development (by backcasting and forecasting). Furthermore, this process is fully 
supported by a collection of interesting pictures of buildings, restaurants, hotels, abandoned areas, the general atmosphere, and spaces (urban faces) that can be considered as important factors for the district's future sustainable development.

Based on these most representative pictures of the NDSM-district, which illustrate both positive and negative aspects, four representative urban faces emerged, and were presented to a group of important stakeholders (from artists to entrepreneurs), operating in and around the NDSM-district, during a semistructured interview. This was done in order to find the optimal level of revitalization to maximize their strategic options and opportunities for future sustainable development. Figure 3 presents the four strategic urban faces of the NDSM district as they exist at present.

Figure 3. The four most representative pictures of the NDSM-district.

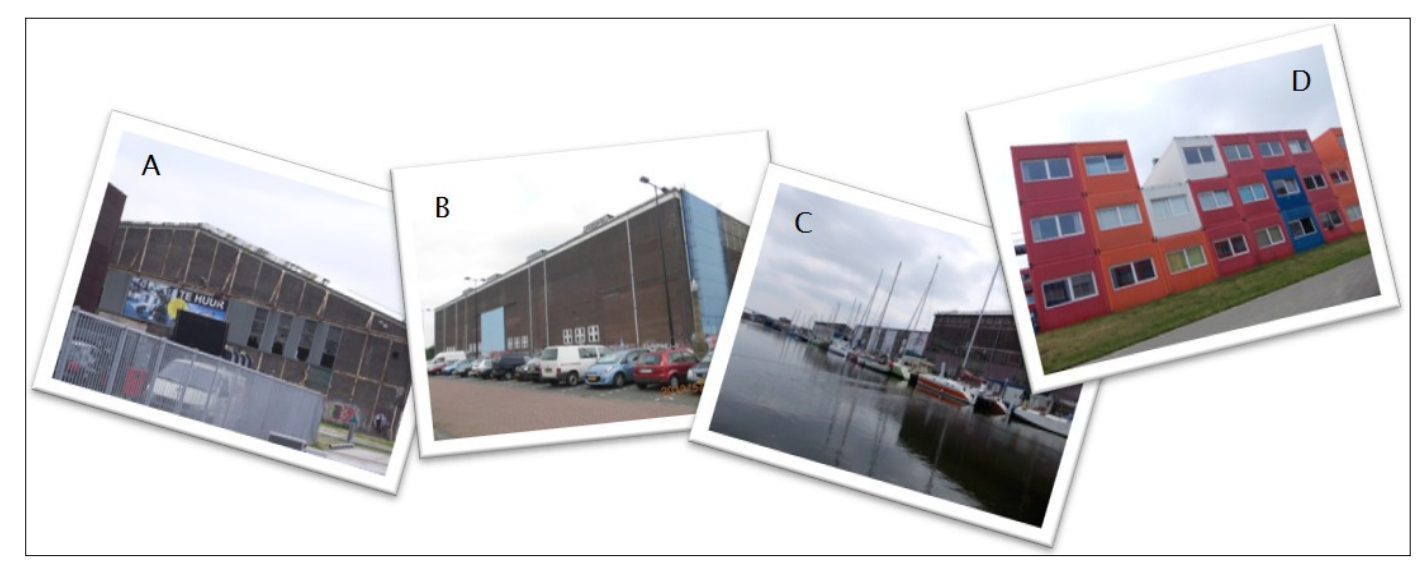

These four strategic urban faces are based on two dimensions: first, the combination of historical heritage (tangible and intangible) and modernity, regarding the functionality and architecture of the district; and, second, either piecewise (project) or integrated (program) redevelopment of the district. From this point of view, a 'strategic future urban faces diagram' can be created in which specific levels of revitalization are distinguished (see Figure 4). These four strategic urban faces cover both local and global scales.

To evaluate the performance of these four strategic urban faces, each stakeholder was asked to rank each urban face with a score, varying from ' $1=$ low' to ' 5 = very high', according to a long list of criteria (pairwise comparison of indicators) (see Appendix A, Table A1) extracted from the SWOT analysis. Interviewees were also asked if there were other important indicators they have had experienced. The long list of criteria gathered from extensive interviews with various stakeholders and literature sources on, respectively, the negative and positive benefits of the NDSM area (in a SWOT analysis) was then systematized and summarized by means of a Principal Component Analysis (PCA). This enabled us to extract the four most important strategic components: namely, economic vitality; accessibility; cultural diversity; and ecological sustainability (for details of the PCA see Appendix B, Tables B1 and B2 and Figure B1).

To link the long-term strategies to short- and medium-term operations, these strategic domains have to be translated into a new potential vision of the NDSM district that can lead to a clear strategic direction and effective related actions. Thus the focus on these strategic domains needs a clear interdisciplinary orientation that is centered on the future sustainability of the port city system, which 
may bring breakthrough innovations on that could reinforce the creative bubble of mixed activities and multifunctionality in and around the NDSM district.

Figure 4. Four strategic future urban faces.

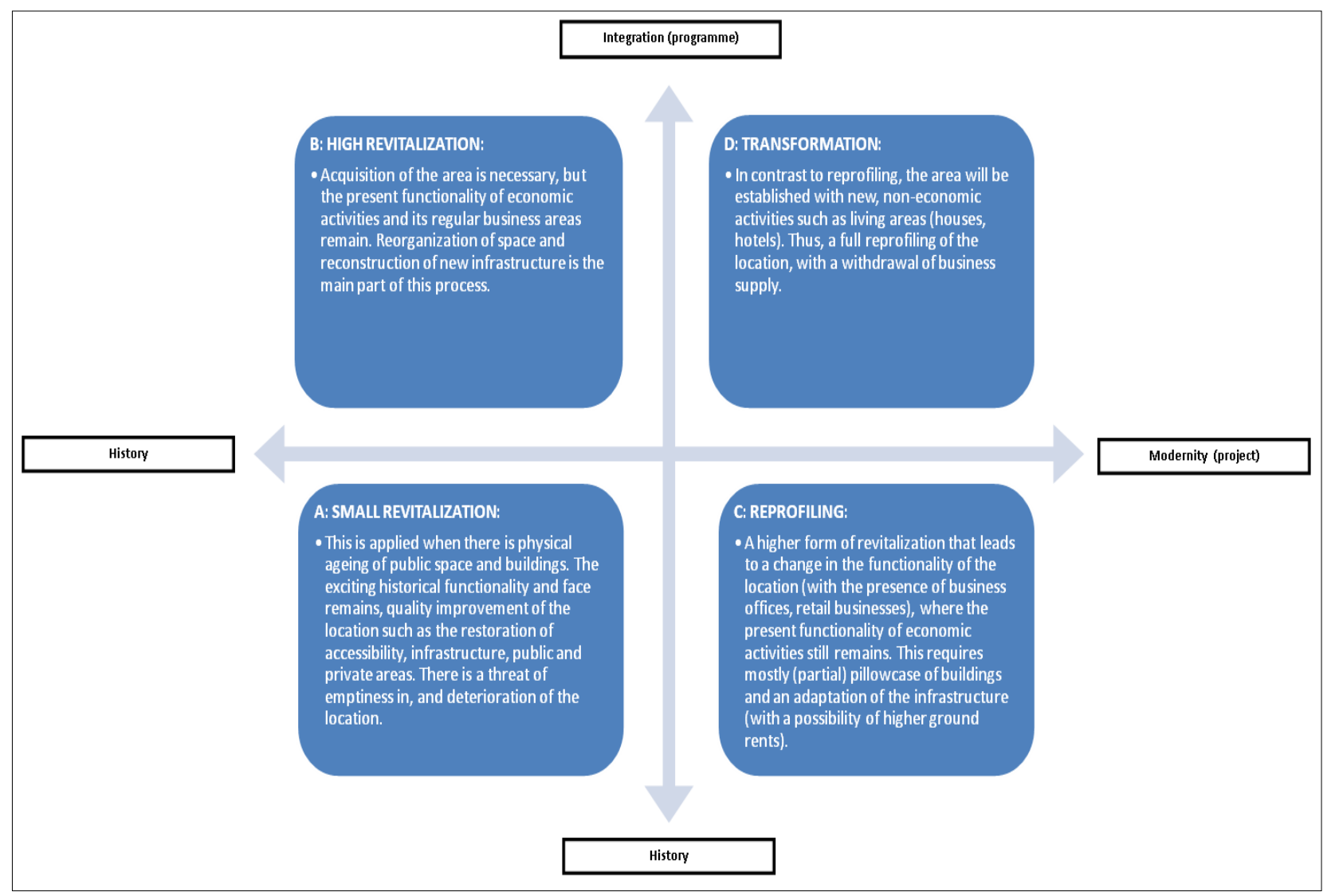

Table 2 shows the long list of indicators that we used to evaluate each of the four components with regard to the values and preferences of the four strategic urban faces. The NDSM-district calls for strategic public governance systems that reinforce its potential. To assess the 'competitive advantage' a la Porter of such new urban governance systems, it is necessary to design a relevant indicator system that shapes the multilevel creative resources of this urban district. This is also a necessary step for a benchmark performance analysis of the success and failure conditions of urban policy. Clearly, such indicators should be transparent, manageable, testable, comparable, representative, and policy-relevant [15].

Next, to extract from these main domains systematic and coherent viable long-term strategies for sustainable urban development, we adopted four related thematic alternatives, which we called 'urban future images' of stylized appearances of urban agglomerations in the year 2050, introduced for the first time in Nijkamp and Kourtit [16]. These urban images may be used as strategic vehicles to identify important challenges and foundations for the innovative development of the NDSM district towards a new 'urban facelift' (by forecasting and backcasting approaches). These strategic alternatives are briefly described in Table 3. Thus, to evaluate the performance of these four strategic urban faces (A-D), each stakeholder was asked to rank each urban face with a rating, varying from ' 1 = low' to ' 5 = very high' in the context of the four alternative 'urban images 2050 ' - in a structured impact matrix, where the alternatives refer to future developments of the NDSM district. 
Table 2. Evaluation indicators of the four components with regard to the values and preferences of strategic urban faces.

\begin{tabular}{|c|c|}
\hline Main domains & Criteria \\
\hline Accessibility \& Learning School & $\begin{array}{l}\text { Independent ultimate events venue } \\
\text { Enjoyment } \\
\text { Dynamic 'oasis' } \\
\text { Accessibility } \\
\text { Independence \& creative atmosphere } \\
\text { Learning } \\
\text { Function } \\
\text { Transportation }\end{array}$ \\
\hline Innovation \& Economic Vitality & $\begin{array}{l}\text { Urban socio-economic climate } \\
\text { Traditional workspaces and activities } \\
\text { Cultural profile } \\
\text { Creative image } \\
\text { Strong cultural and creative profile } \\
\text { Business climate } \\
\text { Long-term strategies } \\
\text { Quality of life and sustainability }\end{array}$ \\
\hline Cultural Diversity \& Entrance & $\begin{array}{l}\text { Quality of urban life } \\
\text { Demography } \\
\text { Cultural amenities } \\
\text { Low rent }\end{array}$ \\
\hline Quality \& Ecological Sustainability & $\begin{array}{l}\text { Urban design and architecture } \\
\text { Urban land use } \\
\text { Criminality }\end{array}$ \\
\hline
\end{tabular}

Source: authors' elaboration.

The images in this Facebook are based on smart-physical and immaterial-infrastructure. All of their elements are centered on a spatially integrated force field for the NDSM-area that entrances the competitive capacities of different stakeholders in that area. In a recent study [15], various analytical contributions can be found, such as the FIRES-Quare model, the XXQ Pentagon model, the leader and organizing capacity approach, or the smart infrastructure model.

This 'urban Facebook' framework has found support from previous scientifically orientated works that have shifted the focus of evaluation models in policy design and urban planning towards the sustainable development of the diversity of the important values and preferences relating to urban areas. This includes the need for the involvement of different stakeholders whose preferences and values are associated with these areas, in the process of design, and ultimately implementation. Examples of such works are: 'strategic choice analysis' [14]; the evaluation of historical districts in cities [17]; and the assessment of district visual quality in the location decisions of creative entrepreneurs [18]. 
Table 3. Strategic Choice Impact Matrix.

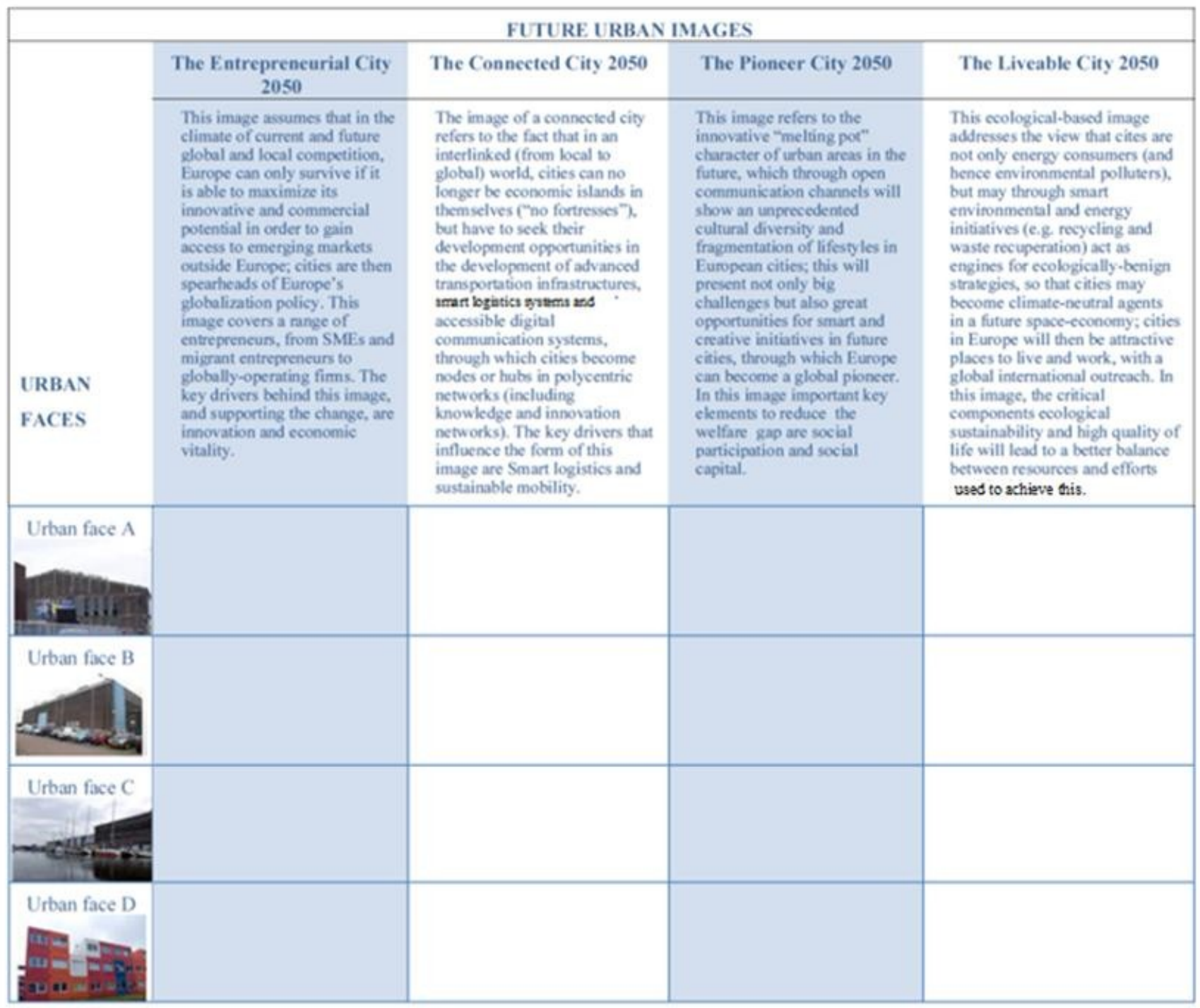

Source: authors' elaboration.

This approach improves and increases the ability to recognize the importance of understanding the characteristics of an area and the preferences for socio-economic and environmental values, including the involvement of all stakeholders' interests in a way that brings and keeps them together, and thus offers a broader perspective regarding the district's sustainable development. It is noteworthy that the local authority has to realize that it needs the support of important stakeholders (private companies and, for instance, representatives of civic organizations) to make the revitalization and the implementation of urban facelifts successful. It is of the utmost importance to distinguish the various stakeholders, and involve them in the planning process of sustainable development under uncertainty.

\section{NDSM State of the Art: SWOT Analysis}

To position the impacts on the NDSM-district in a broader strategic context of socio-economic benefits, this section give a systematic overview of the various effects, mainly in the form of a Strength-Weakness Opportunities-Threats (SWOT) analysis, in which past, current, and future effects 
are assessed from a broad perspective, extensively supported by the strategic urban faces (A-D) [14]. This review results in the construction of a list of the impacts on the NDSM-district that is used here as a case study. In this connection, the stakeholders were asked to identify and to prioritize the most important strength (S) and weakness (W) factors for the NDSM-district from a long-term strategic perspective for the distinct domains of innovation development and cultural diversity importance (derived from the strategic view concerning the future of the NDSM-area).

The results in Tables 4 and 5 show the key factors, as identified by the various stakeholders in the process, including both the $\mathrm{S}$ and $\mathrm{W}$ elements. These data indicate the relevant factors of both domains of the NDSM district, along with their impact on the elements Opportunities (O) and Threats (T). This information represents the vital and creative contribution of creative minds to the urban economy, and can aid the development of appropriate strategic policies for countries [14]. Tables 4 and 5 present the impacts from the SWOT analysis undertaken in this section, and will be used later in this paper as an input in the framework developed for identifying the level of revitalization necessary to achieve a new urban facelift and related strategies with regard to the NDSM-district.

Table 4. SWOT analysis_-innovation development.

\begin{tabular}{ll}
\hline & Innovation Development \\
\hline Strengths (S) & Weaknesses (W) \\
\hline 1. Innovation force $* * *$ & 1. Below-average growth $* * *$ \\
2. Creative industry $* * *$ & 2. Transfer abroad $* * *$ \\
3. Innovative cluster & 3. Recognition of creative minds \\
4. Entrepreneurship & 4. Poor professionalization \\
5. Strength of competition & 5. No long-term strategies or clear vision \\
6. Economic growth & 6. Youth participation \\
7. Supply of affordable work and living spaces & 7. Traditional sectors \\
\hline Opportunities (O) & Threats (T) \\
\hline 1. New innovative products and services & \\
2. New markets & \\
3. Urban vitality & \\
4. Launch new initiatives & \\
5. Employment opportunities & 1. Poor institutionalization $* * *$ \\
6. Creative business climate & 2. Rise of the informal economy $* * *$ \\
7. Internationalization of the city & 3. Temporary area projects \\
8. Knowledge spillovers & \\
9. International contacts & \\
10. Enhancement of small- \& medium-sized businesses & \\
11. Sustainable competition & \\
\hline
\end{tabular}


Table 5. SWOT analysis - cultural diversity.

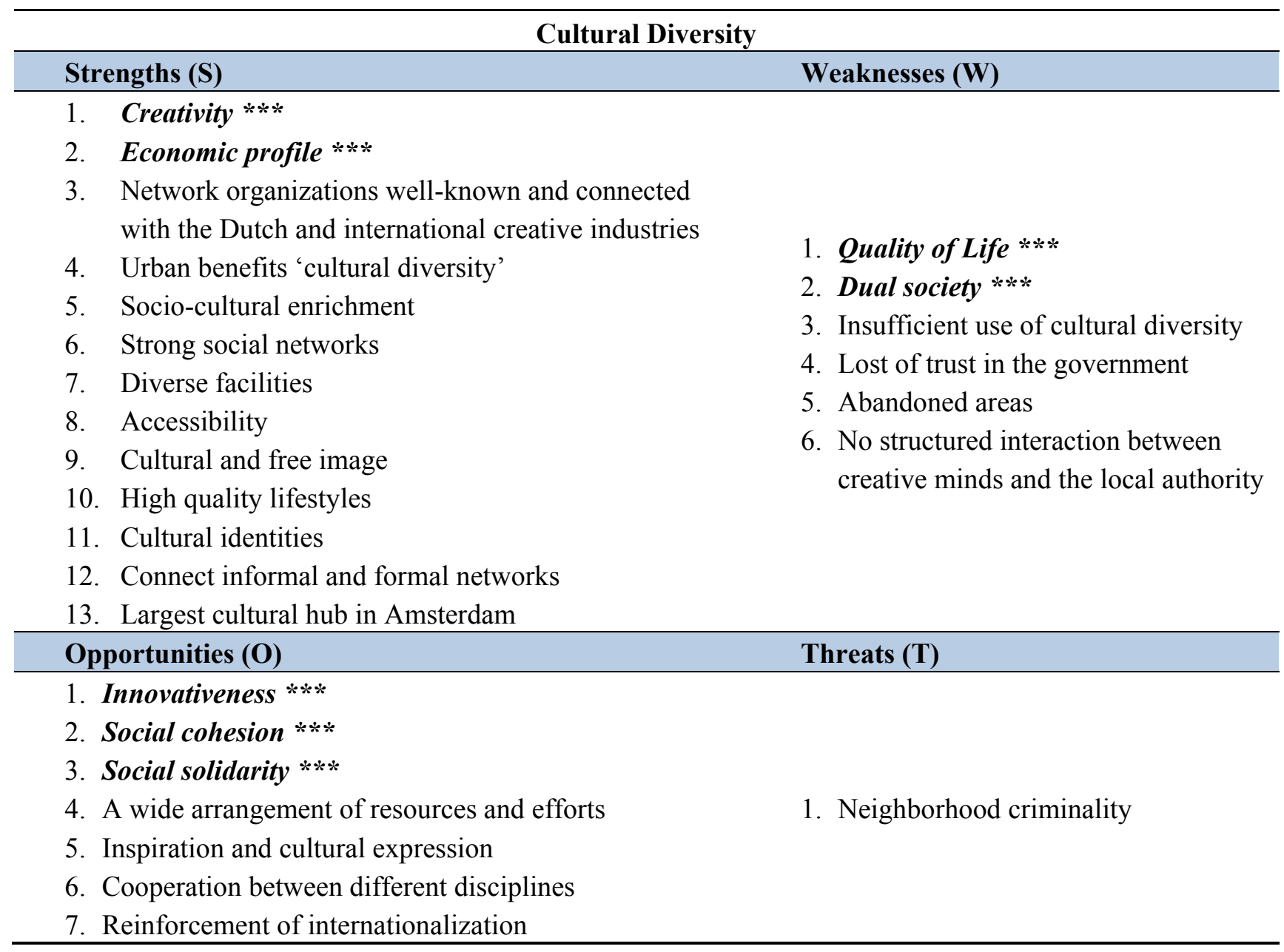

Source: authors' elaboration.

Table 4 shows that the majority of the stakeholders valued innovation force and creative industry (S1 and S2) as the most important strengths, which have a strong impact on new products, new markets, urban vitality and also the creative business climate $(\mathrm{O} 1, \mathrm{O} 2, \mathrm{O} 3$ and $\mathrm{O} 4)$. Where below average growth and transfer abroad (W1 and W2) were identified as the most important weaknesses, these have a strong impact on poor institutionalization, the rise of the informal economy (T1 en T2), and urban vitality (O3).

Table 5 shows that the majority of the stakeholders were convinced that creativity and a strong economic profile of businesses (S1 and S2) are the most important strengths, and both have a strong impact on innovativeness (O1) and neighborhood criminality (T1). However, quality of life and the dual society (W1 and W2) are experienced as the most important weaknesses, both having a strong impact on social solidarity, social cohesion (O2 en O3), and neighborhood criminality (T1).

In recent years, the creative industries [19] have received increasing attention from policymakers in the Netherlands, particularly in Amsterdam, where long-term policies for these industries are included in strategic city policies and the planning of several different fields. Amsterdam is the base for a rich diversity of cultural and economic activities, including international-related knowledge-intensive activities. It has developed many policy strategies that aim to attract the firms of the creative industries, especially SMEs, in order to encourage the further development of this promising sector for 
socio-economic growth. Abandoned industrial locations like the former NDSM shipyard are being gradually transformed stage by stage into attractive locations as 'creative and innovative hubs' with a 'cool' image for a growing number of talented and skilled firms and people in both the creative and other industries.

Nowadays, the NDSM district is the largest cultural hub in Amsterdam, and offers facilities for several artistic disciplines. Thus, the area is not only a geographic hub for the bohemians, but is also becoming a strong 'innovative cluster' for various firms in the creative industries. Over the years, it has become the place for the creation of employment opportunities and the supply of affordable work and living spaces, and it has presented a cultural and unconstrained image for potential users of the district. All this plays an important role in the development and maintenance of high-quality lifestyles and cultural identities within the city. It brings together several informal and formal networks that create added value (incl. inspiration, cultural expression opportunities, cooperation between different disciplines). Furthermore, it encourages innovation forces in the creative industries and the launch of new initiatives (e.g., PICNIC, CCAA, Amsterdam Creativity Exchange, Amsterdam Innovation Motor, HTNK), new products, and the development of new market segments (most artists cannot live from the art market alone), which all contribute to the attractiveness and vitality, and an increase in the national and international appeal of the port and city system. Already in 1989, Harvey stated that "it particularly does so when an urban terrain is opened for display, fashion and the 'presentation of self' in a surrounding of spectacle and play. If everyone, from punks and rap artists to the 'yuppies' and the haute bourgeoisie can participate in the production of an urban image through their production of social space, then all can at least feel some sense of belonging to that place" ([20], p.13).

Unfortunately, the cultural diversity of this 'urban terrain' in Amsterdam is insufficiently used as a cultural, economic and international asset for the broadening and growth of the creative industries, which could put the area on the international map. In the opinion of the various actors, the importance and presence of these available innovative businesses, and their trendy products and services for the various market (mostly highly segmented) that provide future income sources, have not been sufficiently recognized by the public and the government.

The creative professionals do often not interact with the local authority on a structural basis. However, the new initiatives (network organizations) are well known and have connections with the Dutch and international creative industries both to stimulate their maturity and professionalization and to improve their economic performance. They open their informal and formal networks for the creative industries in order to develop a coaching and managing trajectory (a one-stop-shop for the creative industries) and increase the wide provision of resources and efforts that play a very important role in halting the neglect of areas. Furthermore, by enhancing their cultural position, realizing a varied and high-quality image (the general atmosphere and hospitality), bundling and strengthening their innovative powers, increasing national and international knowledge sharing and contemporary collaborations of different partners and firms (social cohesion and social solidarity), they help to turn a raw talent into a potential and professional entrepreneur and attract international sponsors and large projects (e.g., the Red Light Fashion Amsterdam Project, Redlight Design Amsterdam) for establishing cross-cultural collaborations, creative and innovative networks and (formally) strengthening Amsterdam's international cultural reputation and the city's economic growth (and the decline of the informal economy in this district). 
It would help to invest more in the development of creative and cultural competences and talents (entrepreneurial skills) and to connect the chain of cultural and economic activities, as the NDSM-district could stimulate high quality cultural production and international trade-connections. Therefore, it is important to: create opportunities to stimulate young creative and innovative entrepreneurs; encourage their creativity, professional development (economic independence) and entrepreneurship; market their activities more efficiently; and innovate in order to adjust to changing markets, both locally and internationally. Therefore, opportunities to share knowledge, exchange information and gain access to international market segments are very important. In this respect, the interdisciplinary engagement of innovative professionals from different fields, such as architecture, music, and art, would provide an opportunity to develop innovative products.

In conclusion, the NDSM-district is a good example of a source of creativity and innovation, but is still lacking a clear and robust vision to develop a 'sustainable home'. This increases the risk of losing important of growth opportunities to transform or improve the district and city's image into a cultural and creative 'safari' that clearly reflects its unique identity and high values, including the involvement of creative minds and their preferences in order to develop a shared vision that illustrates a strong synergy of collective expertise and development plans. This new approach leads to new opportunities for different levels of revitalization, in the transformation from a historical industrial area into a more healthy creative urban bubble of mixed functions. Here, the innovative hub with its cultural activities serves several more goals than just providing a cheap place to work and live. Moreover, it clearly stimulates a social infrastructure or network and contributes to the cultural enrichment of a city.

The next section takes a closer look at the possibility to have an 'urban facebook for urban facelifts' for the NDSM shipyard, based on the preferences of creative minds and the value they put on the NDSM district.

\section{An Urban Facebook for Facelifts}

The SWOT analysis resulted in an overview that respects the history of the area and integrates many of the historic elements, in order to identify its potential 'look' and find the optimum solution for the area by taking into consideration the stakeholders' opinions and points of view. Based on the SWOT analysis and the strategic and visual assessment derived from the interviews, our Strategic Choice Analysis (SCA) — as a vehicle for assessing and developing strategic policies for the development of the NDSM district—aims to identify [14]:

- the most important Strength factors to be used to participate in, or take advantage of, Opportunities (SO strategies) and to counter or avoid Threats (ST strategies) with regard to the various levels of revitalization;

- the most important Weakness factor to be eliminated (SO) or improved in order to be able to participate in Opportunities (WO strategies) and to counter or avoid the impact of Threats (WT strategies) with regard to the various levels of revitalization;

- the most important strategic proposals to be used to take advantage of the Strengths and Opportunities detected or to avoid the Weaknesses and Threats identified with regard to the various levels of revitalization. 
The results are organized according to the importance of the NDSM landscape, future strategies, the needs, preferences, and values of the users, and the safari-profile defined as policy guidelines for the sustainable development of the area. To determine the degree of importance of the various levels of revitalization, the rank order of the urban faces ranges from 0 points for each irrelevant impact to 5 points for the most important impacts. After multiplying each score with its given importance classes, we are then able to synthesize all scores to determine the strongest factors for the two relevant, socio-economic domains derived from the strategic view for the NDSM district. Once all the important factors have been reviewed in order to assess perceived importance categories, strategic choices are then made by selecting the particular urban face that will most greatly influence policy strategies, viz. a combination of $\mathrm{S}$ and $\mathrm{W}$ elements for the two relevant socio-economic areas of the NDSM area, along with their impact on $\mathrm{O}$ and $\mathrm{T}$. All this information can aid in the development of appropriate strategic policies for the port and city, including the NDSM district [14].

In Section 4, several challenges and opportunities were identified for the transformation and improvement of the NDSM-district, with a view to providing a balanced future for an XXQ urban system (based on the 'XXQ' principle that refers to the highest possible urban quality [21]). According to this, the unique NDSM area definitely needs a clear and transparent long-term strategy that takes into consideration both the entire potential of the place and the individual preferences, in order to ensure a high degree of transparency and future security. The spider diagram in Figure 5 represents the importance and values with regard to the levels of revitalization recommended by various stakeholders, according to the long list of criteria considered in the urban facebook evaluation system.

Figure 5. Visual representation of the various levels of revitalization recommended by the stakeholders.

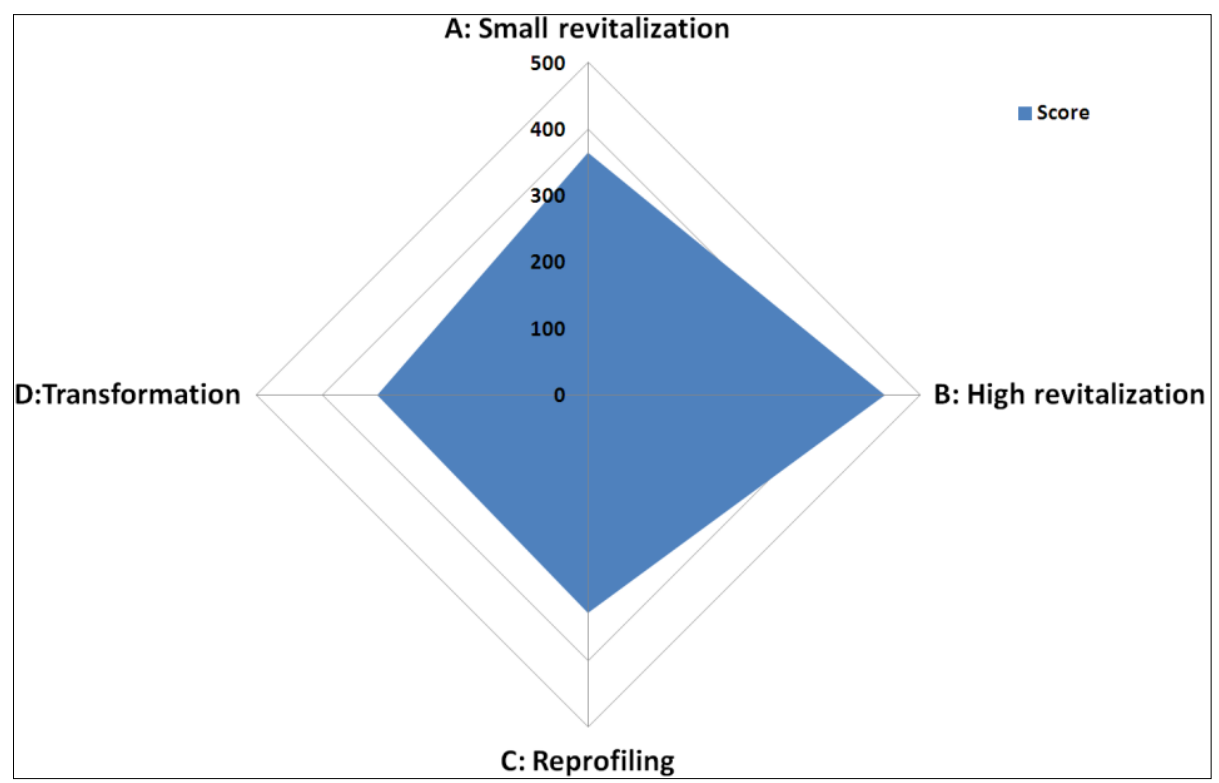

The findings shown in Figure 5 indicate that, on the basis of the long list of criteria, Urban Face B that envisages a high degree of revitalization for the NDSM district is considered by the majority to be the most important and preferable strategic choice for it to become a place for a variety of events and cultural activities which can bring visitors and business into the area. The second preferred strategic 
option for the district is Urban Face A with a small degree of revitalization, where the presence of different users and socio-economic segments and activities in and around the district, including professional needs and interests will arise in the (re)development process. The results show that Urban Faces $C$ and D compared with the other two Urban Faces play a less dominant role in the preferences.

Figure 6 shows that Urban Face A includes a combination of key effective forces, such as creative atmosphere (score: 19), learning (score: 19), accessibility (score: 18), independent events venue (score: 17), dynamic 'oasis' (score: 17), traditional workspaces and activities (score: 18), all of which are driving evolutionary and successful change, in an overall transition from a weak to a strong multi-functional and energetic creative hub.

Figure 6. The criteria scores of the urban faces.

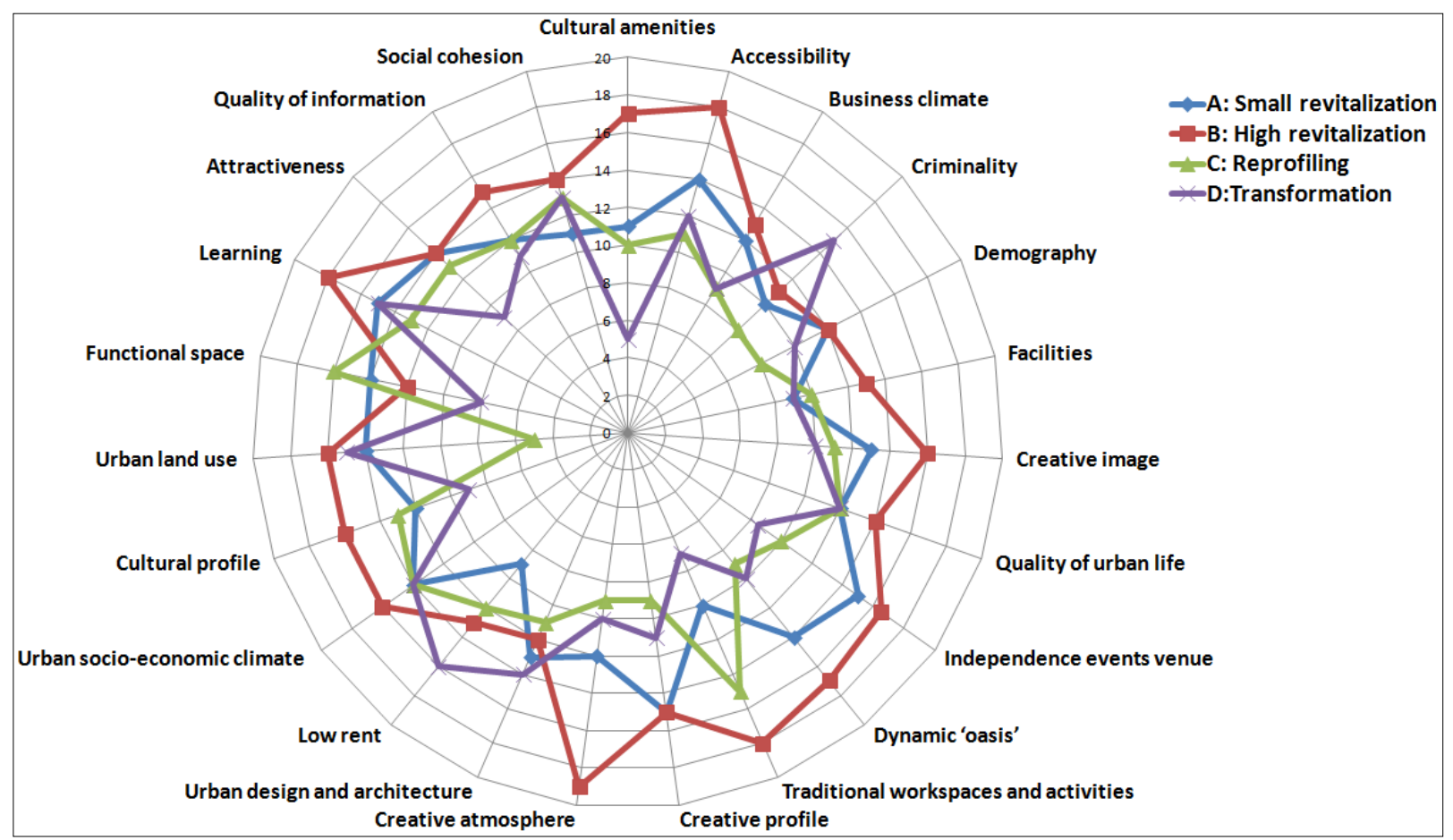

The NDSM area is a place of creativity and innovation (the main strengths of the area), and is currently being experienced as a 'warm nest for creative minds', and a place that provides the creative inspiration that the stakeholders need in order to develop their projects, and where they can develop their entrepreneurial skills without being disturbed. Furthermore, it is a perfect place for all kinds of events. The community consists of young creative pioneers - the average age of the entrepreneurs in the NDSM is very low, so the area can become a place for the young generation to start their business and enrich their professional experience (in sustainability learning centers supported by innovation forces). Thus, it is a 'welcome place' for start-ups where the creative and innovative community is consolidated and always willing to help. This presents a potential 'look' that maintains the district's important historical originality and architecture, but with a strong recommendation for the reorganization of space and the reconstruction of new infrastructure, while simultaneously preserving the cultural values.

However, the need for a long-term strategy for the area is still felt strongly among the creative minds, although they did not always agree with the previous transformations and direction of 
(re)development. For example, event planners would like to attract more tourists to this area, while the artists do not agree with this idea. However, they do share certain opinions based on their field of activities, and do believe that is necessary to strike a balance between independence (to give a feeling of creative freedom to various people about all the possibilities of the area) and efficient regulation and policies, and a balance between the need to revitalize the economic side of the area (tourism) and the possibility to be able to explore their creativity (core business) without constraints.

Finally, they still do not see a clear relation between the selected pictures and the criteria to score the performance of the Urban Faces in and around the NDSM-district. This brings our research study to the next level in the urban Facebook framework and a prompt breakthrough, based on the list of criteria, in developing a realistic future potential look ('Urban Face') and a place 4 all. The lack of clear long-term strategies and steering mechanism (governance strategies) may distort people's perception and points of view. This suggests the need to create a complex 'welcome image' regarding the history and the current use of the area in order to adopt an integrated approach for the realistic metamorphosis of the area - including the involvement of all stakeholders' interests, which brings and keeps them together and offers a broader perspective regarding the district's sustainable development.

In conclusion, the presence of the creative bubble of mixed functionality of cultural and economic activities, historical buildings and historic values, and memories is perceived as very important and represents a welcoming image of the area. However, the need to further revitalize the space and provide new infrastructure and networks is still an important part of this process. In this respect, the integrated approach of the local authority to the notion of 'creative community' is noteworthy. This embraces different sets of common preferences and options that together address issues in the evaluation process, and come up with the development of innovative solutions in order to prevent the area from declining in its attractiveness for the various stakeholders, who would subsequently experience a degradation in their quality of urban life (the 'XXQ' principle [19]); and, from a broader perspective, to ameliorate the socio-economic issues.

\section{Urban Future Images NDSM-District}

To evaluate the strategic position of the Urban Faces for the NDSM-district towards a place 4 all for future sustainable development, it is necessary to look at the present situation in terms of the performance across the different viable future image areas: the Entrepreneurial City, the Connected City, the Pioneer City, and the Livable City. These four future images highlight the strategic dimensions of urban futures in Europe. They lend themselves to systemic approaches for the future positioning of the NDSM-district, and reflect the need for strategic thinking on the governance of urban agglomerations for this area from different future perspectives. The ranking levels that each Urban Face achieves in a particular future urban image are: low (1); medium (2); high (3); and very high (4) (pairwise comparison) in order to identify which urban face fits best in different future circumstances in 2050. Figure 7 presents photos A-D in an order that best fits the importance of, and preferences for the four Urban Faces, in order to develop a shared vision and strategies that could lead to new opportunities for different preferences. 
Figure 7. Urban faces positioned in best-fit urban perspectives.

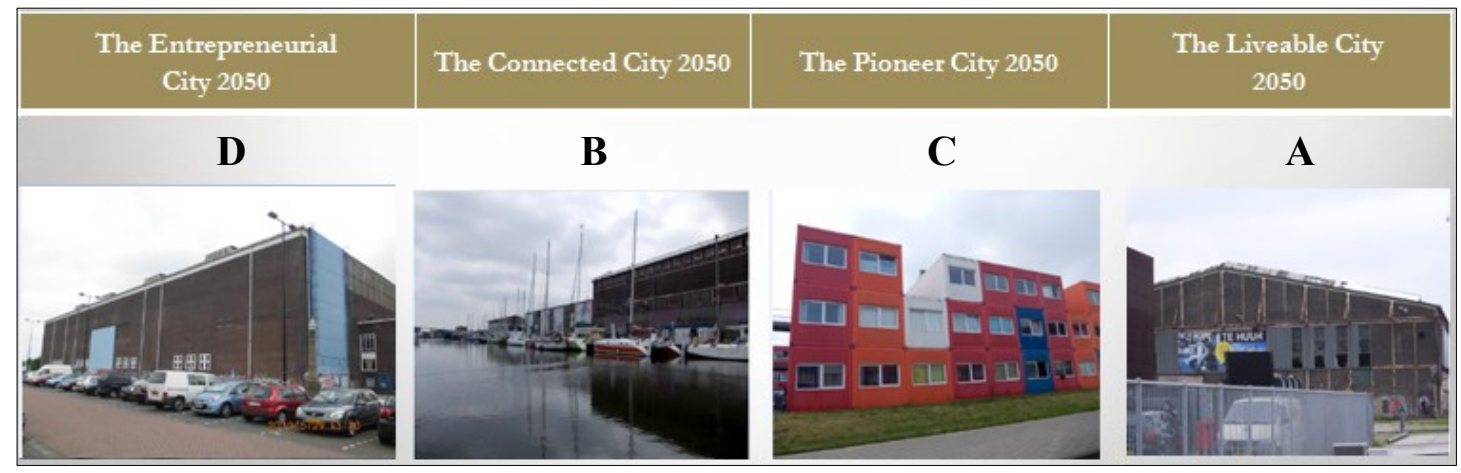

\section{A. Livable City 2050}

Urban face A is strongly related to the Livable City 2050. This image shows a more or less abandoned area and buildings with no clear environmental function or relation to general city policy strategies for the coming years. However, it has strong historical value and special historical memories. Therefore, various stakeholders strongly prefer to keep its original structure and make it a liveable place for eco-tourists and visitors who visit the area for ecological reasons. This approach definitively needs high revitalization. This image perspective envisions the area as a place to live and for leisure activities, in other words, as a residential area.

\section{B. Connected City 2050}

This image focuses more on the connection between the NDSM-district and other parts of Amsterdam in terms of transport and infrastructure. This image refers more to the Connected City 2050, where just a small degree of revitalization is required. A few modifications are needed regarding this image to value its potential as a factor for the accessibility of the area.

\section{Pioneer City 2050}

This image needs a total transformation in order to keep the vibe ('spiky environment') in the area on a high level instead of only being a cheap 'sleeping place' for students — which leads us strongly to the Pioneer City 2050. However, students are a source of creativity and innovation, and need to be involved in this dynamic knowledge arena. This image is more connected to an entrepreneurial perspective that is open to new technologies and has the potential for innovation.

\section{Entrepreneurial City 2050}

In this case this area would be focused on creative business and start-ups. The building in Photo D and part of the area have an important meaning for all the people living and working in the NDSM district due to their history and activities during the weekend (a market has been opened inside). This area is not fully used. An option would be to give entrepreneurs more freedom and space to develop all kinds of activities in this area and inside the building so that the place may become more productive. According to various stakeholders, this Urban Face will need new functions, and therefore it has to be included in the reprofiling category.

In conclusion, the lesson from the previous analysis is that the local authority should involve various stakeholders and gain their trust in (re)developing a positioning strategy towards a high level 
of transparency, and a high level of productive environment that can positively affect issues such as social segregation, housing policy, infrastructure and logistics, environmental sustainability, urban land use, smart energy use, negative urban externalities, and the NDSM district's (international) competitive position. All this requires novel insights and policy strategies in order to make the future 'a place 4 all'.

This would give the area the opportunity to have a new kind of urban facelift in the form of the Welcome City 2050. The new image addresses the view that cities in an open world have always been a place of cultural exchange. The urban multi-historical component plays a key role in determining the identity, diversity, and cultural richness of the port and city system. In this image, both the port and city become an attraction pole for a rising number of international creative minds and tourists. The area is culturally and ethnically located in a strong diverse metropolitan area. Historically, different groups and activities in and around the district have populated this area, in which these groups have actually been seeking spatial segregation to strengthen the cultural and creative identity of this district, as is often the case with immigrant groups.

There is strong collaboration between the creative entrepreneurs working in the NDSM-district, mostly based on technical issues and part of their product value chain. The very act of sharing a workplace and/or working with people full of passion regarding their work and being helpful when needed can play an important role in their positioning strategy. Furthermore, the industrial and rough nature of the area, the free spirit, and being close to people who have the same interests are also factors which are considered to be as important in the location-decision of these entrepreneurs and affects their productivity. Therefore, the potential 'look' to become a 'warm nest for creative minds' is a realistic mission to achieve in order to build an extraordinary community that strongly contributes to the city's sustainable development, and includes them in the long term strategies (see Figure 8).

Figure 8. An interconnected view of the new 'NDSM-district' architecture.

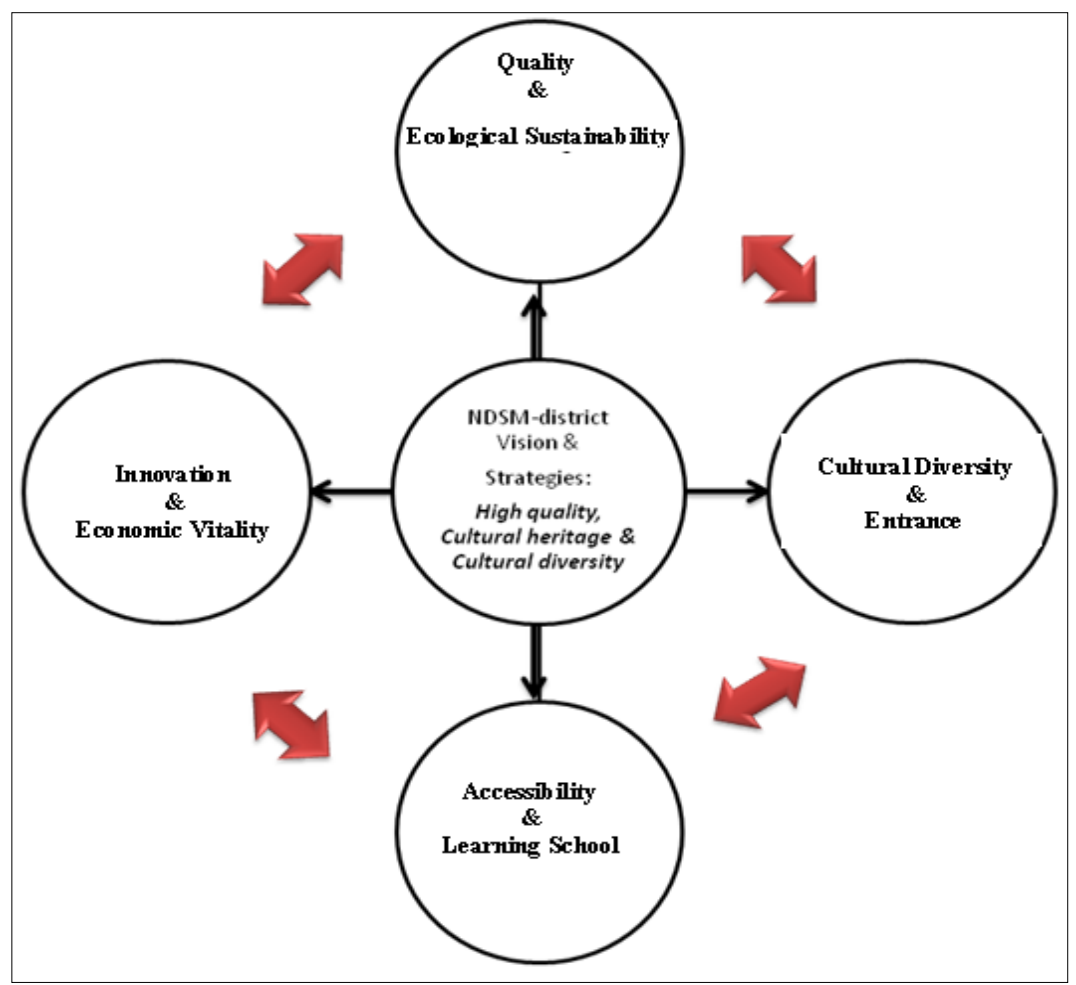


This image of intense revitalization and transformation prompts the need for a new intervention in innovative developments with regard to cultural modernity, with a clear focus on spaces of social interaction and cultural integration, and the enlargement of the variety of facilities, through the high-quality urban design and equipment of those spaces in the process of the creation of a place 4 all. This will make Amsterdam once more a place where energy is generated, which is a continuous process. This new identity is central to the overall transformation of Amsterdam North, with the adaptation or transformation of an older waterfront into a contemporary creative bubble of mixed functions.

This image refers to the innovative 'melting pot' character of urban areas in the future. There will be an unprecedented cultural diversity and fragmentation of lifestyles in and around this district; this will present not only big challenges but also great opportunities for smart and creative initiatives in the future city, whereby it can become a global pioneer. This environment provides various opportunities and solutions to create a connection between artists, economic activities, citizens and government. In other words, a further democratic development of a city-in-a city, what we call the City 2.0, which provides the perfect opportunity to create a living lab in a cultural city of high quality.

\section{Discussion and Conclusions}

Clearly, cities are not only engines of economic progress, but are also places where cultural heritage is prominent. This also holds for port cities, which house a wealth of remains from the past: warehouses, silos, wharfs, lighthouses, industrial architecture, and so forth. It seems therefore, plausible to seek the anchor points of the urban rehabilitation of port areas in their undervalued land use related to logistic port activities from the past. It is noteworthy that the NDSM dockyard is being transformed further to have a more independent atmosphere with less support from the local authority, more successful and autonomous businesses, and ultimately an events venue (such as Robodock). It is becoming the largest cultural and creative project in terms of the city of Amsterdam's core breeding place policy.

Nowadays, port areas - even in a state of decay — often constitute the entry point and core area for the sustainable development of the entire urban system. Port areas offer an unprecedented heritage of a political, architectural, logistic, economic, social and artistic nature, with a great future potential. To understand and exploit this potential, it will be necessary to design an analytical framework which links the manifold opportunities provided by traditional port areas to future sustainable and creative urban development. This challenging objective needs a combination of forecasting and backcasting tools. From that perspective, there is a need to develop fit-for-purpose, dedicated policy tools and gentrification initiatives, on the basis of general planning principles for harborfront and seafront development. An ambitious implementation of policy goals associated with port development—such as job creation, foreign direct investment, creative sector development, environmentally-benign mobility, or sustainable land use-would thus become a major task for a modern port city. It will indeed be a great challenge to redesign and re-image port areas as multifunctional epicenters of creative urban initiatives and developments. These can essentially be seen as living laboratories and innovative urban areas for the development of sustainable practices in an extraordinarily innovative work and residential environment. Such living labs benefit from highly interactive socio-economic activities among firms, residents, universities and research institutes, as well as governmental 
institutions and organizations, which all shape the urban innovation system and highlight its role as a bubbling creative cauldron of centers of excellence. This aspect has to be addressed in the context of any port city re-development plan with a lively mix of activities comprising specific patterns, heritage components, demographic developments, economic situations, future potential and international connectivity links, in order to make sustainability work and to improve international competitiveness.

This study has provided, on the basis of structured interviews, an overview of experience and findings that address the socio-economic impacts of the NDSM district in a broader context. In reinventing the port areas, the urban Facebook framework, first developed in Kourtit and Nijkamp [14]) helped us to identify successful strategic policies, and to bring together different expertise to balance: conflicts between the interests and values of a multiplicity of stakeholders; and economic prosperity with social needs and the conservation of eco-systems. In other words, a preference elicitation exercise was organized through the main focus group of users of the NDSM district, while the systematically collected information was analyzed within the urban Facebook evaluation framework, which includes a visual support tool (i.e., the four Urban Faces). This present framework adopts the same general idea, but extends it by recognizing the importance of the visual appearance of the urban cultural ambience and urban future images and ambitions of historic and modern urban districts, based on a stakeholderoriented (a bottom-up approach). In this framework, visual features and values were integrated in a set of urban future images, which map out different levels of urban planning on the basis of a set of different evaluation criteria. Thus, the framework is a direct action platform that offers social utilities to connect various people who work and live together, supported by high-quality visual assessment tools, for mapping novel redevelopment initiatives.

Taking into consideration each stakeholder's preferences, values, and point of view on the area helps to attract and keep creative minds living and working to develop flourishing, dynamic economies. Each stakeholder has his/her own option and vision for the area. This diversity has helped to create more complex and accurate future images of the area. Thus, a possible (ranging from little to strong) facelift aim of the NDSM-district is to attract and retain creative, high-skilled people, creative firms, etc. to formerly neglected areas in order to achieve sustainable development.

A prerequisite for a promising revitalization policy is that port cities should be able to develop highly innovative strategic approaches to urban planning, conservation and management that really integrate harbor development with urban development. Indeed, both the organizational and economic innovation of the urban space is key to improving the resilience of a port city system, and thus its overall sustainability.

\section{Acknowledgments}

The authors wish to thank several Romanian students, who as part of their internship assisted in collecting the necessary data.

\section{Conflicts of Interest}

The authors declare no conflict of interest. 


\section{References}

1. Atkinson, R. Packing the Bunker. Urban Stud. 2006, 43, 819-832.

2. Butler, T. Living in the Bubble. Urban Stud. 2003, 43, 2469-2486.

3. Watt, P. Living in an Oasis. Environ Plan. A 2009, 41, 2874-2892.

4. Kourtit, K.; Möhlmann, J.; Nijkamp, P.; Rouwendal, J. The spatial distribution of creative industries and cultural capital in the Netherlands. J. Cult. Herit. Man. Sustain. Dev. 2013, forthcoming.

5. Rutten, P.; Manshanden, W.; Muskes, J.; Koops, O. De Creatieve Industrie in Amsterdam en de Regio; TNO: Delft, The Netherlands, 2004.

6. SBI. Standaard Bedrijfsindeling (Standard Industrial Classification 1993); Statistics Netherlands (CBS): The Hague, The Netherlands, 1993.

7. Biggs, R.; Raudsepp-Hearne, C.; Atkinson-Palombo, C.; Bohensky, E.; Boyd, E.; Cundill, G.; Fox, H.; Ingram, S.; Kok, K.; Spehar, S.; et al. Linking futures across scales: A dialog on multiscale scenarios. Ecol. Soc. 2007, 12, 17-20.

8. Tress, B.; Tress, G. Scenario visualisation for participatory landscape planning: A study from Denmark. Landsc. Urban Plan. 2003, 64, 161-178.

9. Robinson, J. Future subjunctive: Backcasting as social learning. Futures 2003, 35, 839-856.

10. De Boer, J.; Beekmans, J. Check-in-stedenbouw. Rooilijn 2012, 45, 404-409.

11. Florida, R. Entrepreneurship, Creativity, and Regional Economic Growth. In The Emergence of Entrepreneurship Policy; Hart, D.M., Ed.; Cambridge University Press: Cambridge, UK, 2003, pp. 39-58.

12. Martin, P.; Mayer, T.; Mayneris, F. Spatial Concentration and Firm-Level Productivity in France, Discussion Paper Series 6858; CEPR: Paris, France, 2008.

13. Brain, B.J.L. Cities as systems within systems of cities. Pap. Reg. Sci. Assoc. 1964, 10, 147-163.

14. Kourtit, K.; Nijkamp, P. Strategic choice analysis by expert panels for migration impact assessment. Int. J. Bus. Glob. 2011, 7, 166-194.

15. Nijkamp, P.; Zwetsloot, F.; van der Wal, S. Innovation and growth potentials of European regions: A meta-multicriteria analysis. Eur. Plan. Stud. 2010, 18, 595-611.

16. Nijkamp, P.; Kourtit, K. The 'New Urban Europe': Global challenges and local responses in the urban century. Eur. Plan. Stud. 2012, 1, 1-25.

17. Neuts, B.; Nijkamp, P.; van Leeuwen, E. Crowding externalities from tourist use of urban space. Tour. Econ. 2012, 18, 649-670.

18. Smit, A.J. The influence of district visual quality on location decisions of creative entrepreneurs. J. Am. Plan. Assoc. 2011, 27, 167-184.

19. The term 'creative industries' usually refers to those economic activities that generate both tangible and intangible innovative or knowledge-oriented goods and services, which have an income-generating capacity, while the term 'cultural industries' refers to those activities that have an artistic, historic-social, or entertainment connotation [4].

20. Harvey, D. From managerialism to entrepreneurialism: The transformation in urban governance in late capitalism. Geogr. Ann. Ser. B Hum. Geogr. 1989, 71, 3-17.

21. Nijkamp, P. XXQ factors for sustainable urban development: A systems economics view. Romanian J. Reg. Sci. 2008, 2, 1-34. 


\section{Appendix A. Assessment Criteria}

Table A1. Long list of criteria.

\section{Criteria:}

Visual aspects of neighborhoods may attract creative entrepreneurs to certain districts

1. Cultural amenities

2. Accessibility (Is the Urban Face accessible for various users and visitors?)

3. Business climate

4. Criminality

5. Demography

6. Facilities and access to facilities

7. Creative image

8. Quality of urban life

9. $\quad$ Independent ultimate events venue (art and nightlife venues)

10. Dynamic 'oasis'

11. Traditional workspaces and activities

12. Strong cultural and creative profile

13. Independent \& creative atmosphere

14. Long-term strategies

15. Urban design and architecture

16. Low rent

17. Urban socio-economic climate (Does the Urban Face have an impact on the performance

17. of economic sectors such as tourism, hospitality, and businesses?)

Quality of life and sustainability (Does the Urban Face have an impact on the safety [crime rate, vandalism, preventive measures taken], quietness [noise, destruction of local

18. customs/residents, visual intrusion], pollution [air pollution, water pollution, littering], and urban green [supply of green spaces, accessibility of urban green, the area of urban green assigned as cultural/natural heritage?]

19. Cultural profile (Does the Urban Face have an impact on cultural facilities, exhibitions, events, manifestations, and conventions?)

Urban land use (Does the Urban Face have an impact on the buildings, infrastructure

20. facilities (availability of roads, rail, bicycle roads, pavements, pedestrian areas), the perception of the city scope, and urban water systems)

Transportation (Does the Urban Face have an impact on network congestion (traffic

21. congestion, queuing of tourists to enter cultural heritage attractions, accessibility to cultural heritage attractions by public transport), noise (car or airport), and transport safety?)

22. Function (Does the Urban Face have all the functions the users, visitors, etc. need?)

23. Enjoyment (Is the Urban Face enjoyable? Does it contains fun and interesting elements)

24. Learning

25. Participation (Does the Urban Face encourage participation (with both residents and other tourists), and is it rich in terms of stakeholder participation?)

26. Quality of information and up-to-date information (Is the information provided reliable?)

27. Increasing social awareness of the access to cultural heritage values

28. A reduction in social distance between cultures

29. A strengthening of social cohesion

30. Change in visitors behaviour (also in time and place) towards cultural heritage

31. Other.......

32.

. 


\section{Appendix B. Outputs of Principal Component Analysis}

Table B1. Communalities.

\begin{tabular}{lcc}
\hline & Initial & Extraction \\
\hline Cultural amenities & 1.000 & 0.710 \\
Accessibility & 1.000 & 0.840 \\
Business climate & 1.000 & 0.901 \\
Criminality & 1.000 & 0.426 \\
Demography & 1.000 & 0.542 \\
Facilities & 1.000 & 0.779 \\
Creative image & 1.000 & 0.821 \\
Quality of urban life & 1.000 & 0.713 \\
Independent ultimate events venue & 1.000 & 0.824 \\
Dynamic 'oasis' & 1.000 & 0.678 \\
Traditional workspaces and activities & 1.000 & 0.615 \\
Strong cultural and creative profile & 1.000 & 0.677 \\
Independent \& creative atmosphere & 1.000 & 0.665 \\
Long-term strategies & 1.000 & 0.470 \\
Urban design and architecture & 1.000 & 0.593 \\
Low rent & 1.000 & 0.386 \\
Urban socio-economic climate & 1.000 & 0.752 \\
Quality of life and sustainability & 1.000 & 0.508 \\
Cultural profile & 1.000 & 0.600 \\
Urban land use & 1.000 & 0.639 \\
Transportation & 1.000 & 0.475 \\
Function & 1.000 & 0.186 \\
Enjoyment & 1.000 & 0.780 \\
Learning & 1.000 & 0.787 \\
\hline
\end{tabular}

Extraction Method: Principal Component Analysis.

Table B2. Total Variance Explained.

\begin{tabular}{|c|c|c|c|c|c|c|c|c|c|}
\hline \multirow{2}{*}{ Component } & \multicolumn{3}{|c|}{$\begin{array}{c}\text { Initial } \\
\text { Eigenvalues } \\
\end{array}$} & \multicolumn{3}{|c|}{$\begin{array}{l}\text { Extraction Sums of } \\
\text { Squared Loadings }\end{array}$} & \multicolumn{3}{|c|}{$\begin{array}{l}\text { Rotation Sums of } \\
\text { Squared Loadings }\end{array}$} \\
\hline & Total & $\begin{array}{c}\text { \% of } \\
\text { Variance } \\
\end{array}$ & $\begin{array}{c}\text { Cumulative } \\
\% \\
\end{array}$ & Total & $\begin{array}{c}\text { \% of } \\
\text { Variance } \\
\end{array}$ & $\begin{array}{c}\text { Cumulative } \\
\% \\
\end{array}$ & Total & $\begin{array}{c}\text { \% of } \\
\text { Variance } \\
\end{array}$ & $\begin{array}{c}\text { Cumulative } \\
\% \\
\end{array}$ \\
\hline 1 & 7.169 & 29.870 & 29.870 & 7.169 & 29.870 & 29.870 & 4.714 & 19.642 & 19.642 \\
\hline 2 & 3.412 & 14.218 & 44.088 & 3.412 & 14.218 & 44.088 & 4.557 & 18.986 & 38.628 \\
\hline 3 & 2.891 & 12.047 & 56.135 & 2.891 & 12.047 & 56.135 & 3.430 & 14.290 & 52.918 \\
\hline 4 & 1.896 & 7.899 & 64.034 & 1.896 & 7.899 & 64.034 & 2.668 & 11.116 & 64.034 \\
\hline 5 & 1.609 & 6.704 & 70.738 & & & & & & \\
\hline 6 & 1.531 & 6.380 & 77.119 & & & & & & \\
\hline 7 & 1.234 & 5.143 & 82.261 & & & & & & \\
\hline 8 & 1.227 & 5.111 & 87.372 & & & & & & \\
\hline 9 & 0.991 & 4.131 & 91.504 & & & & & & \\
\hline 10 & 0.640 & 2.665 & 94.168 & & & & & & \\
\hline
\end{tabular}


Table B2. Cont.

\begin{tabular}{|c|c|c|c|c|c|c|c|c|c|}
\hline \multirow{2}{*}{ Component } & \multicolumn{3}{|c|}{$\begin{array}{c}\text { Initial } \\
\text { Eigenvalues }\end{array}$} & \multicolumn{3}{|c|}{$\begin{array}{l}\text { Extraction Sums of } \\
\text { Squared Loadings }\end{array}$} & \multicolumn{3}{|c|}{$\begin{array}{l}\text { Rotation Sums of } \\
\text { Squared Loadings }\end{array}$} \\
\hline & Total & $\begin{array}{c}\% \text { of } \\
\text { Variance } \\
\end{array}$ & $\begin{array}{c}\text { Cumulative } \\
\% \\
\end{array}$ & Total & $\begin{array}{c}\text { \% of } \\
\text { Variance } \\
\end{array}$ & $\begin{array}{c}\text { Cumulative } \\
\% \\
\end{array}$ & Total & $\begin{array}{c}\text { \% of } \\
\text { Variance } \\
\end{array}$ & $\begin{array}{c}\text { Cumulative } \\
\% \\
\end{array}$ \\
\hline 11 & 0.452 & 1.884 & 96.053 & & & & & & \\
\hline 12 & 0.344 & 1.435 & 97.488 & & & & & & \\
\hline 13 & 0.290 & 1.209 & 98.697 & & & & & & \\
\hline 14 & 0.153 & 0.637 & 99.334 & & & & & & \\
\hline 15 & 0.103 & 0.429 & 99.762 & & & & & & \\
\hline 16 & 0.057 & 0.238 & 100.000 & & & & & & \\
\hline 17 & $2.859 \mathrm{E}-016$ & $1.191 \mathrm{E}-015$ & 100.000 & & & & & & \\
\hline 18 & $2.038 \mathrm{E}-016$ & 8.492E-016 & 100.000 & & & & & & \\
\hline 19 & $3.567 \mathrm{E}-017$ & $1.486 \mathrm{E}-016$ & 100.000 & & & & & & \\
\hline 20 & $-2.748 \mathrm{E}-018$ & $-1.145 \mathrm{E}-017$ & 100.000 & & & & & & \\
\hline 21 & $-1.867 \mathrm{E}-017$ & $-7.780 \mathrm{E}-017$ & 100.000 & & & & & & \\
\hline 22 & $-9.516 \mathrm{E}-017$ & $-3.965 \mathrm{E}-016$ & 100.000 & & & & & & \\
\hline 23 & $-1.386 \mathrm{E}-016$ & $-5.777 \mathrm{E}-016$ & 100.000 & & & & & & \\
\hline 24 & $-2.682 \mathrm{E}-016$ & $-1.117 \mathrm{E}-015$ & 100.000 & & & & & & \\
\hline
\end{tabular}

Extraction Method: Principal Component Analysis.

Figure B1. Scree Plot.

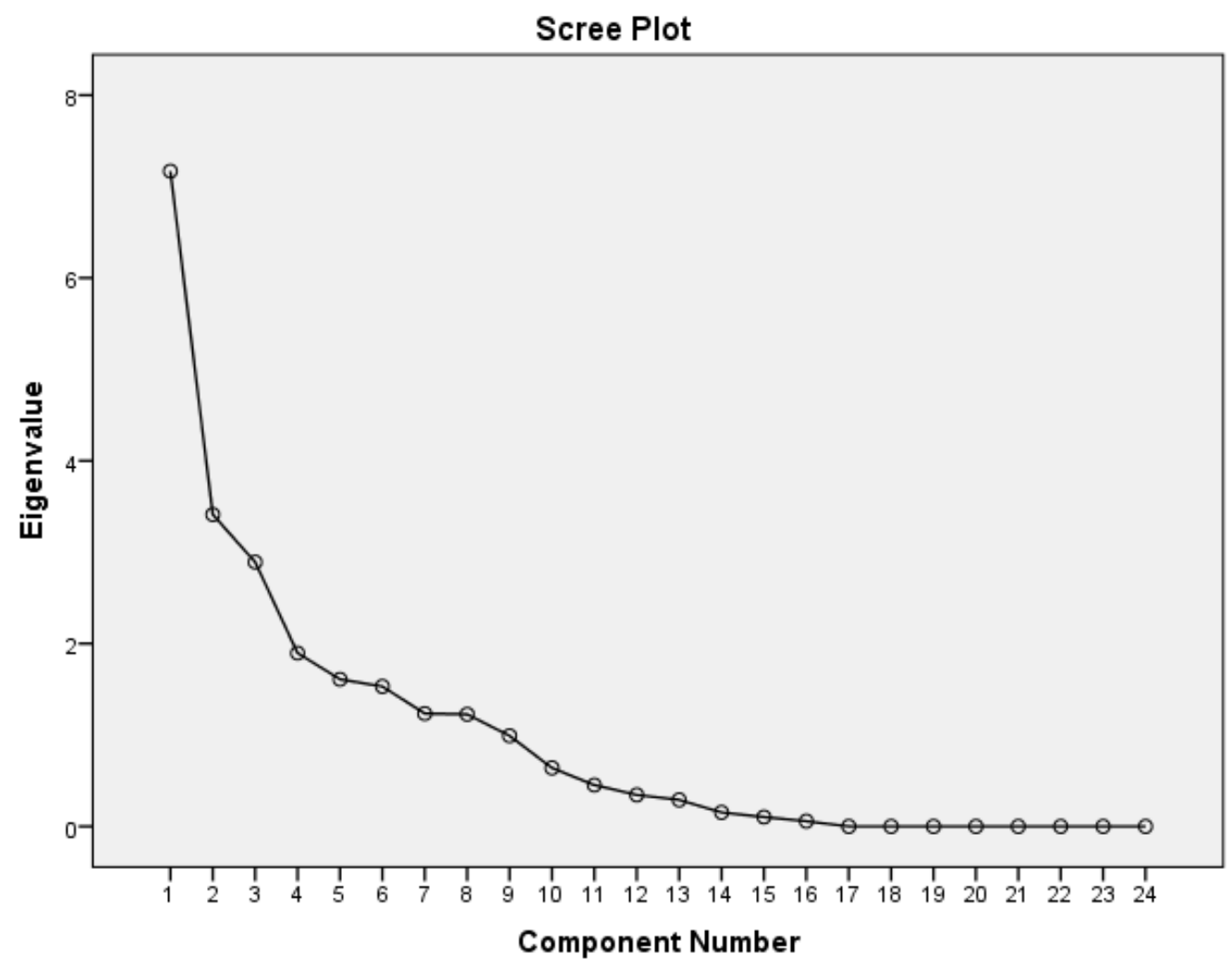


Table B3. Pattern Matrix.

\begin{tabular}{|c|c|c|c|c|}
\hline & \multicolumn{4}{|c|}{ Component } \\
\hline & 1 & 2 & 3 & 4 \\
\hline Independent ultimate events venue & 0.841 & 0.281 & -0.119 & 0.155 \\
\hline Enjoyment & 0.819 & & 0.122 & -0.301 \\
\hline Dynamic 'oasis' & 0.797 & & 0.201 & \\
\hline Accessibility & 0.759 & 0.215 & 0.384 & 0.266 \\
\hline Independent $\&$ creative atmosphere & 0.739 & 0.177 & 0.247 & -0.161 \\
\hline Learning & 0.673 & 0.418 & -0.304 & 0.258 \\
\hline Function & 0.333 & 0.216 & 0.168 & \\
\hline Urban socio-economic climate & & 0.772 & & 0.377 \\
\hline Traditional workspaces and activities & & 0.772 & & \\
\hline Cultural profile & 0.212 & 0.728 & & -0.156 \\
\hline Creative image & 0.517 & 0.720 & -0.186 & \\
\hline Transportation & 0.165 & 0.656 & & 0.111 \\
\hline Strong cultural and creative profile & & 0.636 & 0.241 & 0.455 \\
\hline Business climate & & 0.620 & 0.543 & 0.463 \\
\hline Long-term strategies & 0.292 & 0.553 & & -0.282 \\
\hline Facilities & & -0.107 & 0.870 & \\
\hline Quality of urban life & 0.335 & & 0.718 & -0.289 \\
\hline Demography & & 0.206 & 0.680 & 0.174 \\
\hline Cultural amenities & 0.540 & 0.105 & 0.634 & \\
\hline Low rent & & -0.310 & 0.536 & \\
\hline Urban design and architecture & -0.176 & & & 0.748 \\
\hline Urban land use & 0.322 & 0.101 & & 0.720 \\
\hline Quality of life and sustainability & & 0.405 & 0.245 & -0.526 \\
\hline Criminality & & 0.267 & 0.366 & 0.468 \\
\hline
\end{tabular}

Extraction Method: Principal Component Analysis. Rotation Method: Varimax with Kaiser Normalization. (Rotation converged in 12 iterations).

(C) 2013 by the authors; licensee MDPI, Basel, Switzerland. This article is an open access article distributed under the terms and conditions of the Creative Commons Attribution license (http://creativecommons.org/licenses/by/3.0/). 